\title{
Features of the Fishing Ground Near the Third Nuclear Power Plant in Taiwan
}

\author{
Lei-Zong Cheng \\ Professor, Fortune Institute of Technology, 125-8, Chyi-Shan 842 Kaohsiung Country, Taiwan, 70 Lien-Hai Rd., \\ Kaohsiung, Taiwan 804, R.O.C., ljcheng@center.fjtc.edu.tw \\ Chen-Tung Arthur Chen \\ Professor, Institute of Marine Geology and Chemistry, National Sun Yat-Sen University, 70 Lien-Hai Rd., Kaohsiung, \\ Taiwan 804, R.O.C.
}

Follow this and additional works at: https://jmstt.ntou.edu.tw/journal

Part of the Terrestrial and Aquatic Ecology Commons

\section{Recommended Citation}

Cheng, Lei-Zong and Chen, Chen-Tung Arthur (2004) "Features of the Fishing Ground Near the Third Nuclear Power Plant in Taiwan," Journal of Marine Science and Technology. Vol. 12: Iss. 5, Article 13.

DOI: $10.51400 / 2709-6998.2268$

Available at: https://jmstt.ntou.edu.tw/journal/vol12/iss5/13

This Research Article is brought to you for free and open access by Journal of Marine Science and Technology. It has been accepted for inclusion in Journal of Marine Science and Technology by an authorized editor of Journal of Marine Science and Technology. 


\section{Features of the Fishing Ground Near the Third Nuclear Power Plant in Taiwan}

Acknowledgements

This study was financially supported by the Taiwan Power Company, R.O.C. 


\title{
Short Paper
}

\section{FEATURES OF THE FISHING GROUND NEAR THE THIRD NUCLEAR POWER PLANT IN TAIWAN}

\author{
Lei-Zong Cheng* and Chen-Tung Arthur Chen**
}

Key words: third nuclear power plant, fishing ground, bottom gill net, thermal effluent.

\section{ABSTRACT}

The purpose of this study is to understand the features of the fishing ground near the Third Nuclear Power Plant in Taiwan such as the fish species, catch, the amount of money of catch, the distribution area of fishing ground, cost and income of each voyage. Five adopted fishing rafts were applied in this research to gather relevant data for the investigation from July 1996 to December 2003.

There are 146 kinds of species have been found for the total catches, most of the operating area were located at the center of the sea in which the thermal effluent from the Third Nuclear Power Plant can not reach or influence. Based on the gathered data from the investigation, it is also found that the activities for Herngchuen fishers related to fishing rafts and operating voyages are rare and unimportant.

\section{INTRODUCTION}

The Third Nuclear Power Plant in southern Taiwan was built in 1979, and a large amount of thermal effluent (or thermal plumes) from the nuclear power plant will cause an impact on the ecology of the coastal waters. There are quite a few reports concerned about the thermal effluent causes an impact on the ecological environment. For example, it was reported that the seaweed growth was poor owing to the water temperature over $30^{\circ} \mathrm{C}$ within the range of $300 \mathrm{~m}$ away from the outlet of the thermal effluent (Jeng and Wang, 1987). The foreign authors explained that the thermal effluent will also affect the existence of corals, animals and

Paper Submitted 10/07/04, Accepted 05/05/05. Author for Correspondence: L.Z. Cheng. E-mail: ljcheng@center.fjtc.edu.tw.

*Professor, Fortune Institute of Technology, 125-8, Chyi-Shan 842 Kaohsiung Country, Taiwan, 70 Lien-Hai Rd., Kaohsiung, Taiwan 804, R.O.C.

**Professor, Institute of Marine Geology and Chemistry, National Sun Yat-Sen University, 70 Lien-Hai Rd., Kaohsiung, Taiwan 804, R.O.C. plants (Jones, et al., 1976). Moreover, the variation of the biota living in this waters will affect the growth and bleeding of these organism, and therefore the rise and fall of fishes population in this waters should directly or indirectly influence the income of these fishermen who engage in the fishery in this waters.

The purpose of this study was to access the catch conditions including the catch, the amount of money of catch and meanwhile the composition variation of fishes; the distribution of fishing ground and the availability of fishing ground are also studied. Furthermore, the distribution of fishing ground in the waters near the Nuclear Power Plant are also discussed to determine whether they are affected by thermal effluent or other factors, and which can help to understand the influenced extent to the fishery in this waters.

\section{MATERIALS AND METHODS}

The investigation area of this study was limited in the waters near the Third Nuclear Power Plant which can be seen in Fig. 1. Five adopted fishing rafts engaged in this waters were employed in the project from July 1996 to December 2003. These fishing rafts are less than five tons and the size of gill nets are approximately the same, therefore the fishing efforts can regard as standardized basically. Owing to the operating methods are bottom gill net and catch the benthonic economic fishes which move slowly, the fishing conditions are steady and CPUE (catch per unit effort) is suitable as the index as the economy of fishing ground. The calculate formula for CPUE and IPUE (income per unit effort) can be expressed as follows:

CPUE $=\Sigma \mathrm{X} / \mathrm{n}, \Sigma \mathrm{X}$ represents the sum of the total catch per voyage, whereas $n$ represents the total voyages. On the other hand, IPUE $=\Sigma \mathrm{Y} / \mathrm{n}$ ', $\Sigma \mathrm{Y}$ represents the sum of the amount of money of total catch per voyage, whereas $n$ ' represent the total voyages. 
The main contents in this investigation include the operating days, catch location, the composition of catch fishes, catch weight, the selling price (the amount of money of catch) and the operating cost per voyage (including fuel oil charge, repair charge of fishing gear). According to these informations, such as catch, the amount of money of catch, the distribution area of fishing ground, the conditions of cost and income in each fishermen are analyzed to study the features of the fishing ground in this waters.

\section{RESULTS AND DISCUSSION}

The Third Nuclear Power Plant is located at the western shore of Nanwan Bay at the southern tip of Taiwan. An outline map of the plant site is shown in Fig. 1 (Chiou et al., 1993). The perimeter of Nanwan Bay has a varied coastline. Between the intake area and the outlet of the shoreline is rocky, and south of the outlet of the shoreline is primarily eroded coral rock formations. The outlet is southeastward, and it forms an angle about 52 degrees with the coastline in its right side, and about 155 degrees in its left side. The left side of the outlet is the entrance and exit channels of Hou-Pi$\mathrm{Hu}$ fishing port. According to the fisheries yearbook Taiwan area in 2003, there are 465 fishing rafts at Hou$\mathrm{Pi}-\mathrm{Hu}$ fishing port, but only a few fishing rafts which are less than five tons operate the bottom gill net at Nanwan Bay, and most of the fishing rafts engage in the fishing activities outside Nanwan Bay. Therefore, five sample fishing rafts engaged in this waters were employed for this study from July 1996 to December 2003. The operating time for casting net is at dusk and the raising net is at dawn next day. The monthly variation of CPUE

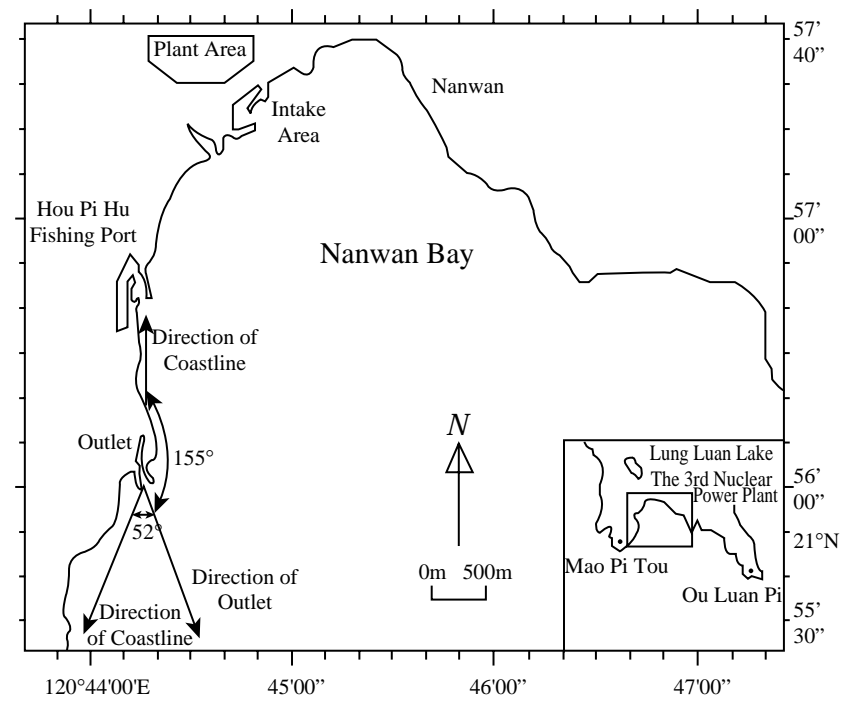

Fig. 1. The investigation area near the Third Nuclear Power Plant. and IPUE from July 1996 to December 2003 was shown in Fig. 2 . According to Fig. 2, it was found that CPUE and IPUE appeared the same tendency that both decreased slowly from July 1996 to April 1998 and then both increased more largely until April 2001 but both decreased slowly again from May 2001 to December 2003. The profit per voyage engaged in this waters appeared the same tendency as CPUE and IPUE in Fig. 2. The numbers of total operation of the bottom gill net were 1964 voyages, CPUE was 40 kilograms, IPUE was 3,618 NT dollars. On the other hand, the operating cost was 1,028 NT dollars per voyage and hence the profit was 2,590 NT dollars per voyage. Most of the caught fishes belong to benthonic and economic fishes such as parrotfish, Japanese sea perch, siganids, snappers, slipper lobster, spiny lobster and so on.

The profit is mainly determined by the factors of catch, operating cost and fishes price, CPUE is slightly changeable and operating cost is almost stable yearly but the variation range of the fishes price is relatively large. Hence, it is suggested that the catch profit in this waters is deeply affected by the fishes price. According to the investigation of these sample fishing rafts, it is found that there are only four days for fishing per month per raft because of the concurrent operating jobs, hence the operating voyages are low in this water, and it can be predicted that the fishing activities to Herngchuen fishmen is not important. There are 146 kinds of species have been found for the total catches from July 1996 to December 2003. According to the sequence species of catch amount in this period, the total catch and the total amount of money of catches within the tenth number are $54 \%$ and $43 \%$, respectively in proportion to the total catches and the total amount of money of catches of all catch fishes in this waters. Although the sequence numbers are different more or less in seven years, the four species of catch are consecutively maintaining within the tenth numbers, therefore, it is suggested that the more catch fishes species are steady in this waters.

According to the statistics of the operating numbers of five sample fishing rafts from July 1996 to December 2003, the distribution of fishing ground in this waters was shown in Fig. 3. The eastern area in this waters is less operating area for fishing rafts, on the other hand most of the operating area are concentrated at the center of this waters. Chiou et al. (1993) suggested that the dispersion of thermal effluent in this waters is mainly affected by SW current which the velocity is more strong than other directions and the dispersion direction is flowing to the western area in this waters and the dispersion range is only limited within 1,000 $\mathrm{m}$ semi-circular area from the center of outlet (Fig. 4). In other words, it can be concluded that the thermal effluent flows southwestward to the western 


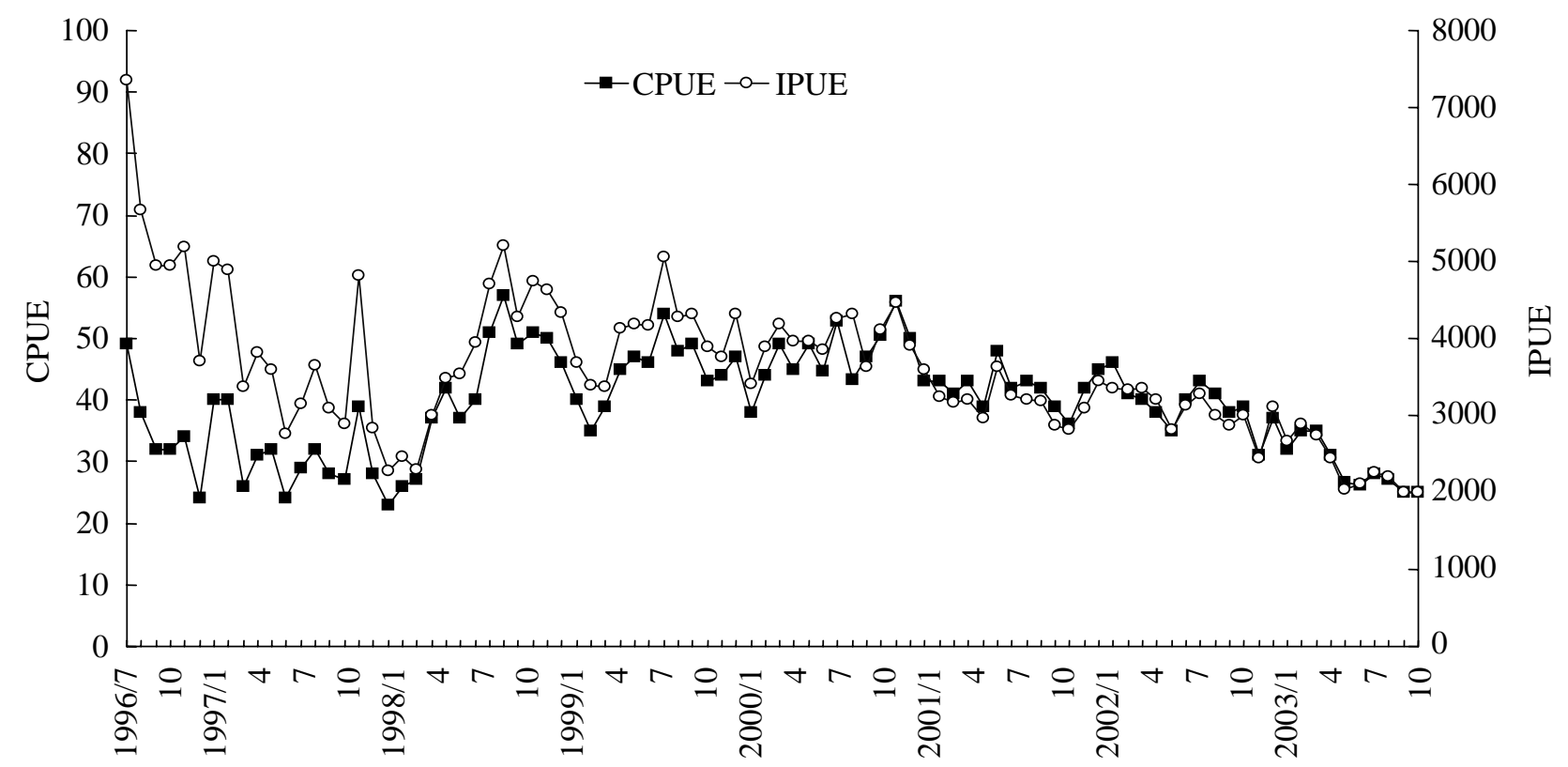

Fig. 2. The monthly variation of CPUE and IPUE of fishing rafts in the waters near the Third Nuclear Power Plant. (CPUE: Kg/voyage, IPUE: NT dollars/voyage)

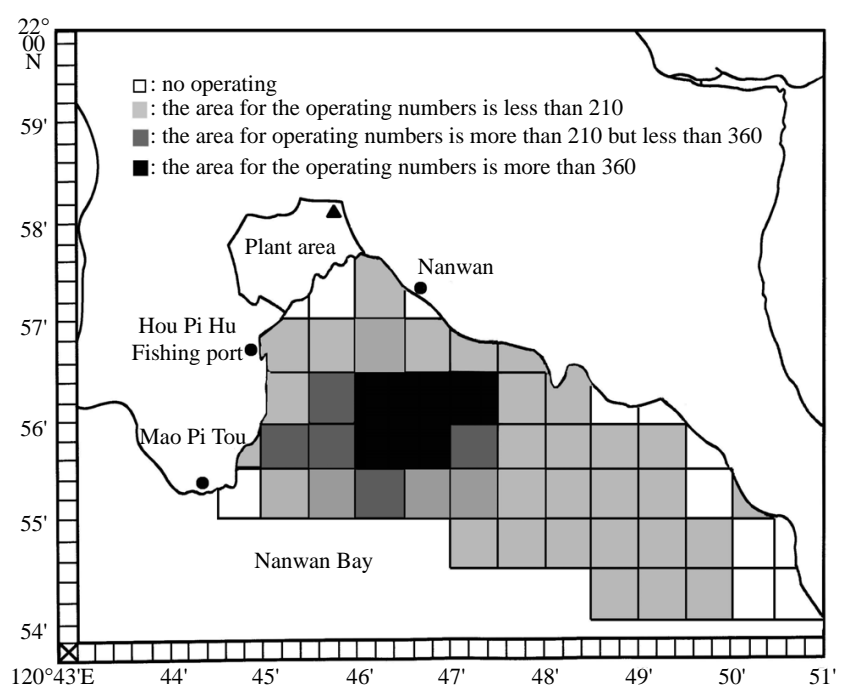

Fig. 3. The distribution of fishing ground in the waters near the Third Nuclear Power Plant, from July 1996 to December 2003.

area and then disperses to Mao Pi Tou, therefore, these concentrated operating fishing ground is apparently not within the dispersed range of thermal effluent.

\section{CONCLUSIONS}

Based on the investigation information gathered from these sample fishing rafts for the features of the fishing ground in the waters near the Third Nuclear

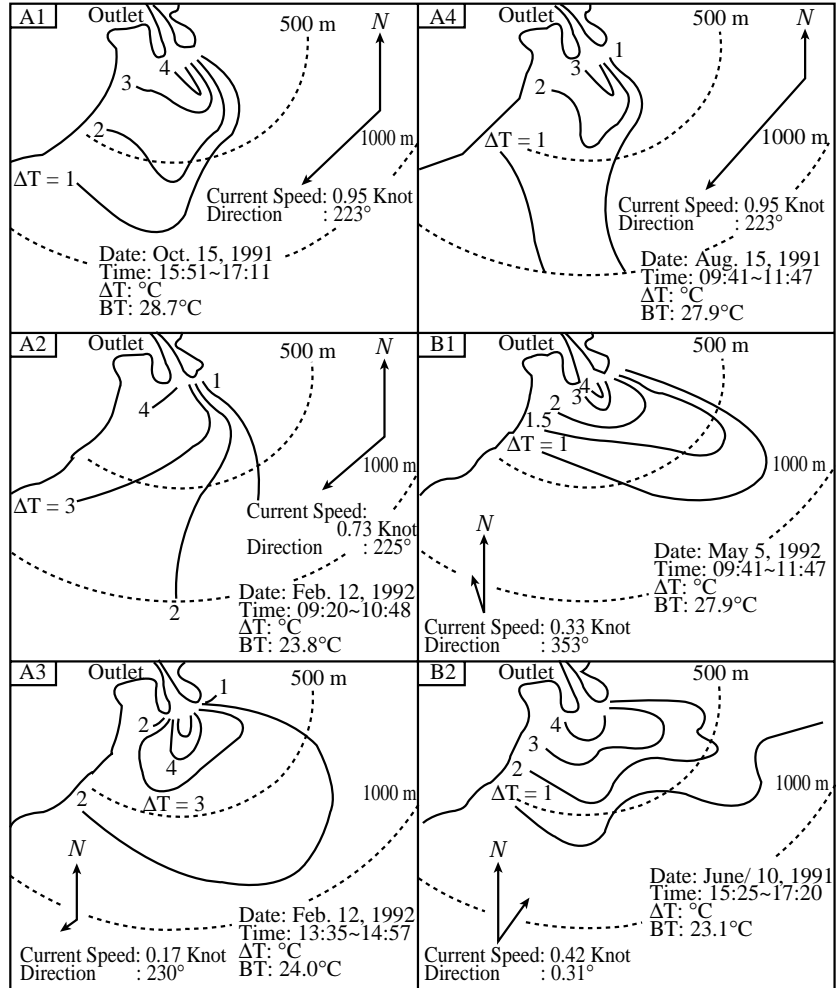

Fig. 4. Surface dispersions of thermal effluent current direction and speed near the outlet of the Third Nuclear Power Plant, from July 1990 to December 1992.

$\Delta \mathrm{T}$ : Temperature rises with respect to background station at the sea surface.

BT: Surface temperature of background station. 
Power Plant from July 1996 to December 2003, it is known that there are a few fishing rafts which engaged in the bottom gill net in this waters and most of the catch are benthonic and high economic fishes, CPUE (catch per unit effort) was 40 kilograms per voyage, IPUE (income per unit effort) was 3,618 NT dollars per voyage, the operating cost of CPUE was 1,028 NT dollars and the profit of CPUE was 2,590 NT dollars. It is also found that there are only 4 days for operating per fishing raft each month, therefore the activities for Herngchuen fishmen related to fishing rafts and operating voyages are rare and unimportant; the mainstream of the fishery activities at Herngchuen district is pole and line fishery, long line fishery, troll line fishery, and marlin fishery that the fishing ground is out of Nanwan Bay. There are 146 kinds of species have been found for the total catches, and the species of more catch fishes are relatively steady in this waters. Based on the distribution area of fishing ground, the fishery operating activity in east side of the investigated area is rare, most of the fishery operating activities were located at the center of the sea in which the thermal effluent from the Third Nuclear Power Plant can not reach or influence.

\section{ACKNOWLEDGEMENTS}

This study was financially supported by the Taiwan Power Company, R.O.C.

\section{REFERENCES}

1. Chiou, W.D., Cheng, L.Z., and Ou, H.C., "Relationship between the Dispersion of Thermal Effluent and the Tidal Current in the Waters Near the Outlet of the Third Nuclear Power Plant in Southern Taiwan," J. Fish. Soc. Taiwan, Vol. 20, No. 3, pp. 207-220 (1993).

2. Jeng, Y.M. and Wang, W.L., "Influence of Thermal Effluent of the Nuclear Power Plant on Seaweed Ecology in the Waters of National Park," Ministry of the Interior Report, No. 44, pp. 1-15 (1987). (in Chinese)

3. Jones, R.S., Randall, R.H., and Wilden, M.J., Biological Impact by Changes on a Tropical Reef, U.S. Environmental Protection Agency, Office of Research and Development, Environmental Research Lab., Narragansett, Rhode Island, EPA-60013-76-0270 (1976). 